\title{
Inserção da Controladoria em Artigos Publicados em Eventos Científicos Nacionais
}

\author{
Inclusion of Controllership in Articles Published in National Scientific Events
}

\author{
Éder Cláudio Bastos \\ Mestre em Ciências Contábeis pela \\ Universidade Regional de Blumenau - \\ FURB
}

\author{
Ilse Maria Beuren \\ Doutora em Controladoria e Contabilidade pela \\ FEA/USP \\ Professora do Programa de Pós-Graduação em \\ Ciências Contábeis e Adminsitração da FURB
}

\begin{abstract}
Resumo
$\mathrm{O}$ artigo tem como objetivo analisar a inserção da controladoria em artigos publicados em anais de eventos científicos nacionais relacionados à área da contabilidade. Trata-se de pesquisa descritiva, realizada por meio de levantamento, com abordagem predominantemente quantitativa. Foram selecionadas publicações do período de 2001 a 2006 do Congresso USP de Controladoria e Contabilidade, ENANPAD e Congresso Brasileiro de Custos, todos eventos qualificados pelo Qualis CAPES. Para análise dos dados utilizou-se de técnica bibliométrica. Os resultados da pesquisa evidenciam os autores mais citados nas referências dos artigos; os autores com maior número de publicações nos eventos; os tipos de pesquisa, procedimentos, técnicas e abordagens utilizadas para elaboração dos artigos; e as instituições com maior número de publicações. Também em outra análise, com abordagem qualitativa, faz uma investigação dos enfoques dados pelos autores em seus trabalhos. Conclui-se que houve um crescimento proporcionalmente maior de artigos de controladoria publicados, levando-se principalmente em consideração os anos de 2005 e 2006, sendo os anos com maior número de artigos sobre o tema. Relativo à metodologia utilizada pelos autores, constatou-se uma deficiência ou dificuldade em classificar seus trabalhos pela sua diversidade.
\end{abstract}

Palavras-chave: Controladoria. Eventos científicos nacionais. Produção científica.

\begin{abstract}
The objective of the article is to analyze the inclusion of Controllership in articles published in annals of national scientific events in the accountancy area. This research is descriptive, conducted through a survey, with a predominantly qualitative approach. Publications from the period of 2001 to 2006 were selected from the USP Controllership and Accountancy Congress, ENANPAD and Brazilian Cost Congress, all events approved by Qualis CAPES. For data analysis a bibliometric technique was used. The results of the research show the authors most cited in the articles references; the authors with the highest number of publications at the events; the types of research, procedures, techniques and approaches used to produce the articles; and the institutions with the highest number of publications. Other research, with a qualitative approach, investigated the main areas of data focused upon by the authors in their work. It was concluded that there was a proportionally greater growth of published controllership articles, when taking principally 2005 and 2006 into account as the years with the largest numbers of published articles on the subject. Concerning the methodology used by the authors: this was either lacking or difficulty was encountered in classifying the work as a result of its diversity.

Keywords: Controllership. National scientific events. Scientific production.
\end{abstract}




\section{INTRODUÇÃO}

A comunicação é elemento indispensável para a atividade científica, uma vez que, sem ela, não existiria ciência e não se poderiam somar os esforços individuais dos membros das comunidades científicas. A comunicação científica, entendida como o conjunto de atividades associadas à disseminação e ao uso da informação, é importante para a aceitação do que é produzido cientificamente.

Os meios formais, pelos quais se processa a comunicação científica, em sua versão primária, abrangem periódicos, teses, dissertações, relatórios, anais etc. Os trabalhos publicados em eventos científicos têm papel importante no fomento da pesquisa e no avanço do conhecimento, mediante divulgação e discussão dos trabalhos, para as mais diversas áreas do conhecimento.

Em decorrência, em determinados momentos da história do conhecimento, o avanço de uma teoria toma outros rumos, revolucionando paradigmas antigos ou melhorando antigos conceitos. A controladoria, que é o foco do presente estudo, desperta o interesse de pesquisadores de diversas áreas do conhecimento, mas especialmente das ciências sociais aplicadas.

Em pesquisas sobre o estudo da comunicação científica a respeito da controladoria, outros trabalhos já foram publicados com algumas características semelhantes. Moriki e Martins (2003) realizaram uma pesquisa com a finalidade de levantar, caracterizar e analisar as referências bibliográficas das dissertações e teses defendidas em 2000 nos programas de pós-graduação em Contabilidade e Controladoria da FEA/USP e da FEA/PUC-SP. As conclusões dos autores neste trabalho levaram a uma reflexão importante, como o conservadorismo quanto às fontes consultadas, concentrando-se em livros e raramente citam periódicos nacionais ou estrangeiros; ignoram publicações de anais, seminários, etc; ocasionalmente referem-se a endereços eletrônicos.

Outra pesquisa realizada por Martins e Silva (2005), com abordagem bibliométrica, buscou levantar, registrar e categorizar as referências de 221 textos envolvendo 3.795 referências utilizadas pelos autores, divulgados no terceiro e quarto Congresso USP de Controladoria e Contabilidade. Os resultados mostraram que os autores desses textos estão, timidamente, dialogando com autores contemporâneos, preferindo uma comprometedora dispersão de tradicionais escritores nacionais sobre contabilidade e controladoria. A heterogeneidade é tanta que não se consegue identificar clássicos nem tampouco um denso corpo de conhecimento do campo contábil, a partir das referências bibliográficas analisadas.

Nesta mesma direção, o objetivo deste estudo é analisar a inserção da controladoria em artigos publicados em anais de eventos científicos nacionais, relacionados à área da contabilidade. O foco é especificamente nos congressos USP, ENANPAD e CUSTOS, no período de 2001 a 2006. A escolha do período inicial deve-se ao lançamento do congresso USP de Controladoria e Contabilidade em 2001 e o final a data de realização da pesquisa.

Como principal fator limitante da pesquisa destaca-se que os artigos foram selecionados para o estudo tendo como critério a palavra controladoria constar no título, palavras-chave ou resumo. Em decorrência, a pesquisa não abrange todos os artigos sobre controladoria publicados nos eventos pesquisados, pois provavelmente diversos trabalhos que abordam sobre artefatos da controladoria não trazem a palavra conforme os critérios de seleção. Porém, o critério justifica-se pela preocupação em não qualificar os artigos erroneamente, uma vez que não se tem estudos que delimitam de forma completa quais são os artefatos da controladoria

São de fundamental importância estudos analíticos de textos que tenham se originado em eventos, tais como congressos, simpósios, seminários e outras categorias de estudos, pois com sua 
exposição surgem novas discussões e dúvidas sobre obras consagradas e já bastante exploradas. A partir desses estudos surgem novas idéias em relação ao assunto, novas formas de abordagem, novas críticas, gerando novos conhecimentos científicos, avaliados pelos experts da área.

O presente artigo está estruturado em cinco seções. Primeiramente, faz uma breve introdução ao objetivo e importância do estudo. Em seguida, apresenta o significado e funções da controladoria. Após aborda sobre indicadores bibliométricos. Na seqüência discorre sobre o método e procedimentos adotados na pesquisa. Por fim, descreve a análise propriamente dita da produção científica brasileira em eventos ao longo dos anos 2001 a 2006, além das conclusões sobre a investigação realizada.

\section{SIGNIFICADO E FUNÇÕES DA CONTROLADORIA}

Em um mundo de transformação, várias mudanças vêm ocorrendo em pouco tempo, implicando cada vez mais em obtenção de maiores vantagens competitivas. No cenário das organizações em todo o mundo, apresenta-se como instrumento relevante a controladoria. Planejar, organizar, racionalizar e gerir, criar estruturas e sistemas com o intuito de levar as organizações ao alcance de seus propósitos, tornou-se indispensável para assegurar a sobrevivência das organizações.

Para Almeida et al. (2001, p. 344), a controladoria não pode ser vista como um método, voltado ao como fazer. Para uma correta compreensão do todo, deve-se cindi-la em dois vértices: a) como ramo do conhecimento responsável pelo estabelecimento de toda a base conceitual; e b) como órgão administrativo respondendo pela disseminação de conhecimento, modelagem e implantação de sistemas de informações.

Assim é responsabilidade da controladoria otimizar as tecnologias da informação, por meio de uma visão sistêmica, com a finalidade de compilar as informações geradas, distribuí-las, auxiliando a alta administração na tomada de decisões. Anderson e Schmidt (1961 apud Mosiman e Fisch 1999, p. 92) citam que as funções da controladoria são decorrentes do desenvolvimento empresarial, compostas de funções essenciais e complementares.

As funções chamadas essenciais, de acordo com esses autores, subdividem-se em: a) controle organizacional, tem como objetivo facilitar a organização e controle de forma eficiente e econômica; e b) mensuração do empreendimento, tem como objetivo identificar e descrever as várias relações de receita e custos com o intuito de suprir e, conseqüentemente, ressaltar o planejamento gerencial inteligente.

Complementando as funções essenciais, novas funções surgiram e que se incorporaram à área de controladoria, também arroladas pelos mesmos autores: a) divulgação de informações para usuários externos à empresa, em decorrência das exigências legais; e b) proteção do patrimônio, com o estabelecimento e manutenção de controles e auditoria interna e garantia de cobertura apropriada para elementos patrimoniais segurados.

Para a operacionalização das funções da controladoria e sua missão dentro das organizações, destaca-se o Controller como o responsável por toda a organização das informações geradas internamente. O Controller é o responsável pela gestão das informações, as quais os gestores utilizam para obter orientações quanto à direção e controle das atividades empresariais. Não é função do Controller a direção dos negócios da empresa, mas sim deixar os gestores informados sobre a melhor forma de gerir a empresa.

Beuren (2002, p. 23) afirma que o Controller deve ter capacidade técnica para realizar as tarefas que lhe são designadas, bem como gerenciar o pessoal subordinado. Sua função dentro da empresa amplia-se num leque de conhecimentos que afetam o ambiente interno e externo da 
empresa, e exigem do Controller estar a par de todos os aspectos que modificam ou poderão modificar a situação da empresa.

Fomentando o que foi relatado a respeito da controladoria, realizou-se um estudo bibliométrico de anais de congressos no período de 2001 a 2006, nos congressos USP, ENANPAD e CUSTOS relacionados ao tema. É nesse contexto que se buscou relacionar trabalhos publicados em eventos nacionais classificados no Sistema do Qualis CAPES relacionados à controladoria.

\section{INDICADORES BILBIOMÉTRICOS}

A bibliometria surge como um recurso para pesquisadores se utilizarem dessa técnica na investigação científica de seus vários interesses, pode ser para fazer uma análise crítica em relação a algum assunto específico, ou também para simples levantamentos de temas de interesse. Pritchard (1969) define bibliometria como a aplicação de métodos matemáticos e estatísticos a livros e outros meios de comunicação, aconselhando sua utilização em todos os estudos que buscassem quantificar o processo de comunicação escrita.

Castro (1985, p. 30) afirma que "a bibliometria nada mais é do que as técnicas de tratar comparações de forma mais completa e rigorosa. Seus ingredientes básicos são, pois, o reaproveitamento de avaliações geradas para outros fins e as técnicas quantitativas para o seu tratamento".

Para orientar as políticas específicas de determinado setor e justificar a atividade científica recorre-se a métodos quantitativos e qualitativos de avaliação. Isto possibilita medir os níveis de desenvolvimento alcançados por uma disciplina, as taxas de produtividade dos pesquisadores envolvidos, a deteç̧ão de instituições e cursos com maior potencial de crescimento e a determinação de escalas de prioridades para a distribuição de recursos.

Toda e qualquer ciência deve ser avaliada periodicamente, a fim de mostrar à sociedade sua importância e seus avanços, dando, desta forma, um retorno do investimento que nela foi aplicado. Para isso a bibliometria utiliza-se de indicadores bibliométricos, que são as medidas quantitativas que buscam representar conceitos muitas vezes intangíveis dentro do universo do fazer da ciência.

Para Mugnaini et al. (2006), como indicadores de resultado, os indicadores bibliométricos são medidas para se avaliar a produtividade de comunidades científicas, a eficácia de um programa em ciência e tecnologia ou a efetividade/impacto da pesquisa na própria ciência ou para o desenvolvimento econômico e social de um país.

Os indicadores bibliométricos cumprem a finalidade de apontar os resultados imediatos e efeitos impactantes do esforço destinado à ciência, constituindo-se a terminologia corrente no campo da formulação e avaliação dos trabalhos científicos. A definição de indicadores pode ser descrita como parâmetros utilizados nos processos de avaliação de qualquer atividade. Empregam-se alguns conjuntos de indicadores, sendo que cada um revelará um lado do objeto em avaliação.

De acordo com Sancho (1990), com indicadores bibliométricos é possível determinar alguns aspectos do trabalho cientifico: a) crescimento de qualquer campo da ciência, segundo a variação cronológica do número de trabalhos publicados; b) o envelhecimento dos campos científicos, segundo a vida média das referências de suas publicações; c) a evolução cronológica da produção científica segundo o ano de publicação dos documentos; d) a produtividade dos autores ou instituições, medida pelo número de trabalhos; e) a colaboração entre os pesquisadores ou instituições, medida pelo número de autores por trabalhos ou centros de pesquisas que colaboram; f) o impacto ou visibilidade das publicações dentro da comunidade científica nacional 
e internacional, medido pelo número de citações que recebem em trabalhos posteriores; g) a análise e avaliação das fontes difusoras dos trabalhos, através de indicadores de impacto das fontes; e h) a dispersão das publicações científicas entre as diversas fontes e quem as está produzindo.

Os indicadores bibliométricos são úteis e importantes para se entender o ciclo de gestação, reprodução e disseminação da ciência e o aprimoramento da política científica. No entanto, isto se computados dentro do rigor metodológico devido, se interpretados a partir das especificidades e práticas de produção bibliográfica de cada área de conhecimento e se entendidos dentro de suas limitações.

\section{METODOLOGIA DA PESQUISA}

O delineamento do presente estudo consiste de pesquisa descritiva, realizada por meio da técnica de levantamento, utilizando indicadores bibliométricos e abordagem quantitativa e qualitativa para os dados coletados.

A pesquisa descritiva, conforme Gil (2006), tem como objetivo primordial a descrição das características de determinada população ou fenômeno ou o estabelecimento de relação entre as variáveis. Dentre as pesquisas descritivas destacam-se as que têm por objetivo estudar e descrever as características de uma população: idade, sexo, nível de escolaridade, nívelde renda, etc.

Por sua vez, a pesquisa de levantamento ou survey, conforme Silva (2003, p. 62), "consiste na coleta de dados referentes a uma dada população com base em amostra selecionada, de forma clara e direta, dos quais se objetiva saber o comportamento". As pesquisas deste tipo caracterizam-se pela análise direta dos dados cujo comportamento se deseja conhecer. Basicamente, procede-se à solicitação das informações e posteriormente mediante análise quantitativa obtém-se as conclusões correspondentes aos dados coletados.

A produção científica sobre o tema "controladoria", na área da contabilidade, foi identificada e analisada por meio de um levantamento em anais do Congresso USP de Controladoria e Contabilidade, ENANPAD e Congresso Brasileiro de Custos, referente o período de 2001 a 2006, cujos eventos foram escolhidos por caracterizarem-se como eventos de contabilidade ou afins ao tema proposto.

As variáveis quantitativas do estudo consideradas foram: os autores mais citados nas referências dos artigos, os autores com maior número de publicações nos eventos, os tipos de pesquisa, procedimentos, técnicas e abordagens utilizadas para elaboração dos artigos, e origem institucional das publicações.

Em outra parte da análise dos artigos, com abordagem eminentemente qualitativa, procurou-se fazer uma investigação dos enfoques encontrados nos trabalhos e suas ligações com a controladoria.

Foram analisados 6.187 artigos científicos publicados entre 2001 e 2006, nos seguintes eventos: Congresso USP de Controladoria e Contabilidade, ENANPAD e Congresso Brasileiro de Custos, conforme Tabela 1. Foram selecionados os artigos com a palavra controladoria no título, no resumo ou nas palavras-chave.

Tabela 1- Artigos publicados nos eventos no período de 2001 a 2006

\begin{tabular}{llccc}
\hline \multirow{2}{*}{ Ano } & Eventos & População & $\begin{array}{c}\text { Artigos } \\
\text { identificados }\end{array}$ & Percentual (\%) \\
\hline \multirow{2}{*}{2001} & USP & 74 & 5 & 0,19 \\
& ENANPAD & 426 & 1 & \\
\hline
\end{tabular}


Continuação

\begin{tabular}{llccc}
\hline Ano & Eventos & População & $\begin{array}{c}\text { Artigos } \\
\text { identificados }\end{array}$ & Percentual (\%) \\
\hline \multirow{2}{*}{2002} & USP & 85 & 1 & 0,21 \\
& ENANPAD & 554 & 2 & 10 \\
2003 & CUSTOS & 207 & 3 & 0,16 \\
& USP & 101 & 1 & 0,14 \\
\hline \multirow{2}{*}{2004} & ENANPAD & 630 & 6 & 0,26 \\
& CUSTOS & 294 & 1 & \\
\hline \multirow{2}{*}{2005} & USP & 100 & 3 & 0,24 \\
& ENANPAD & 799 & 3 & 1,20 \\
\hline \multirow{2}{*}{2006} & CUSTOS & 279 & 3 & 8 \\
\hline TOTPL & ENANPAD & 100 & 4 & 3 \\
\hline
\end{tabular}

Fonte: dados da pesquisa.

Como observado na Tabela 1, do total da população de artigos publicados nos três eventos extraíram-se 74 artigos para análise, representando $1,20 \%$ do total de trabalhos aprovados nos eventos pesquisados.

Da população de referência foram selecionados os artigos que destacaram de forma explícita, através do critério de escolha da presença da palavra "controladoria", constando no título, no resumo ou nas palavras-chave. É importante salientar que os 74 artigos selecionados representam $100 \%$ dos que contêm a palavra controladoria nos eventos anteriormente citados.

Considerando todos os trabalhos analisados, num total de 74, referente o período de 2001 a 2006, constatou-se que o Congresso Brasileiro de Custos foi o evento com maior participação de artigos na pesquisa, totalizando 41 artigos, contra 20 do Congresso USP e 13 do ENANPAD. Esse resultado surpreende um pouco, devido ao Congresso USP de Controladoria e Contabilidade ter menor aprovação de artigos com os requisitos usados pela pesquisa (palavra controladoria no título, no resumo ou palavras-chave) que o Congresso Brasileiro de Custos, embora o evento tenha área temática em controladoria.

\section{DESCRIÇÃO E ANÁLISE DOS RESULTADOS}

Neste tópico procede-se à análise quantitativa das variáveis focalizadas na pesquisa. Ao se levantar dados sobre os artigos selecionados, constataram-se algumas particularidades, que serão discorridas na seqüência.

\subsection{Autores e referências bibliográficas}

A Tabela 2 mostra a distribuição do número de artigos publicados por autor, além do programa ou instituição a que os autores pertencem. No entanto, somente os autores com mais de um artigo publicado nestes eventos no período de 2001 a 2006 foram arrolados. 
Tabela 2- Autores com maior número de publicações nos três eventos

\begin{tabular}{llc}
\hline \multicolumn{1}{c}{ Pesquisador } & \multicolumn{1}{c}{ Programa } & N$^{\circ}$ de artigos \\
\hline Auster Moreira Nascimento & Universidade do Vale do Rio dos Sinos (UNISINOS) & 7 \\
Márcia Bianchi & Universidade do Vale do Rio dos Sinos (UNISINOS) & 4 \\
Luciane Reginato & Universidade do Vale do Rio dos Sinos (UNISINOS) & 3 \\
Juliano Giongo & Universidade do Vale do Rio dos Sinos (UNISINOS) & 2 \\
Maurício Fernando Pocopetz & Pontifícia Universidade Católica de São Paulo (PUC-SP) & 2 \\
Rubens Famá & Pontifícia Universidade Católica de São Paulo (PUC-SP) & 2 \\
Ivam Ricardo Peleias & Centro Universitário Álvares Penteado (UniFECAP) & 2 \\
Cláudio Parisi & Centro Universitário Álvares Penteado (UniFECAP) & 2 \\
Reinaldo Guerreiro & Universidade de São Paulo (USP) & 2 \\
Antônio Robles Júnior & Universidade de São Paulo (USP) & 2 \\
Masayuki Nakagawa & Universidade de São Paulo (USP) & 2 \\
Gilberto Andrade Martins & Universidade de São Paulo (USP) & 2 \\
Valmor Slomski & Universidade de São Paulo (USP) & 2 \\
Ricardo Luiz Menezes da Silva & Universidade de São Paulo (USP - RP) & 2 \\
Paula Carolina Ciampaglia Nardi & Universidade de São Paulo (USP - RP) & 2 \\
Carlos Alberto Grespan Bonacim & Universidade de São Paulo (USP - RP) & 2 \\
Tatiana Albanez & Universidade de São Paulo (USP - RP) & 2 \\
Flávio Valladão Flores Glette & Universidade de São Paulo (USP - RP) & 2 \\
Roberto Vatan dos Santos & Universidade de São Paulo (USP - RP) & 2 \\
Jorge de Souza Pinto & Universidade Federal de Mato Grosso do Sul (UFMS) & 2 \\
Ilse Maria Beuren & Universidade Regional de Blumenau (FURB) & 2 \\
Demais (um artigo por autor) & Diversas Instituições & 24 \\
\hline Fonte: & & \\
\hline
\end{tabular}

Fonte: dados da pesquisa.

Observa-se uma concentração razoável por autor na produção científica sobre controladoria, já que num espaço de 6 anos, 1 autor participou de 7 publicações sobre o tema, outras duas autoras participaram respectivamente de 4 e 3 publicações e outros 18 participaram de 2 publicações cada um e os demais autores todos com participação em apenas 1 publicação.

De acordo com os dados levantados, observa-se na Tabela 2 que Auster Moreira Nascimento, Márcia Bianchi e Luciane Reginato, ambos da UNISINOS, são os pesquisadores com maior número de artigos aprovados nos Congressos USP, ENANPAD e CUSTOS que contém o termo controladoria segundo os critérios estabelecidos na pesquisa nos anos de 2001 a 2006.

No Gráfico 1 demonstra-se a relação do número de autores por artigo, do total de 74 artigos analisados. 


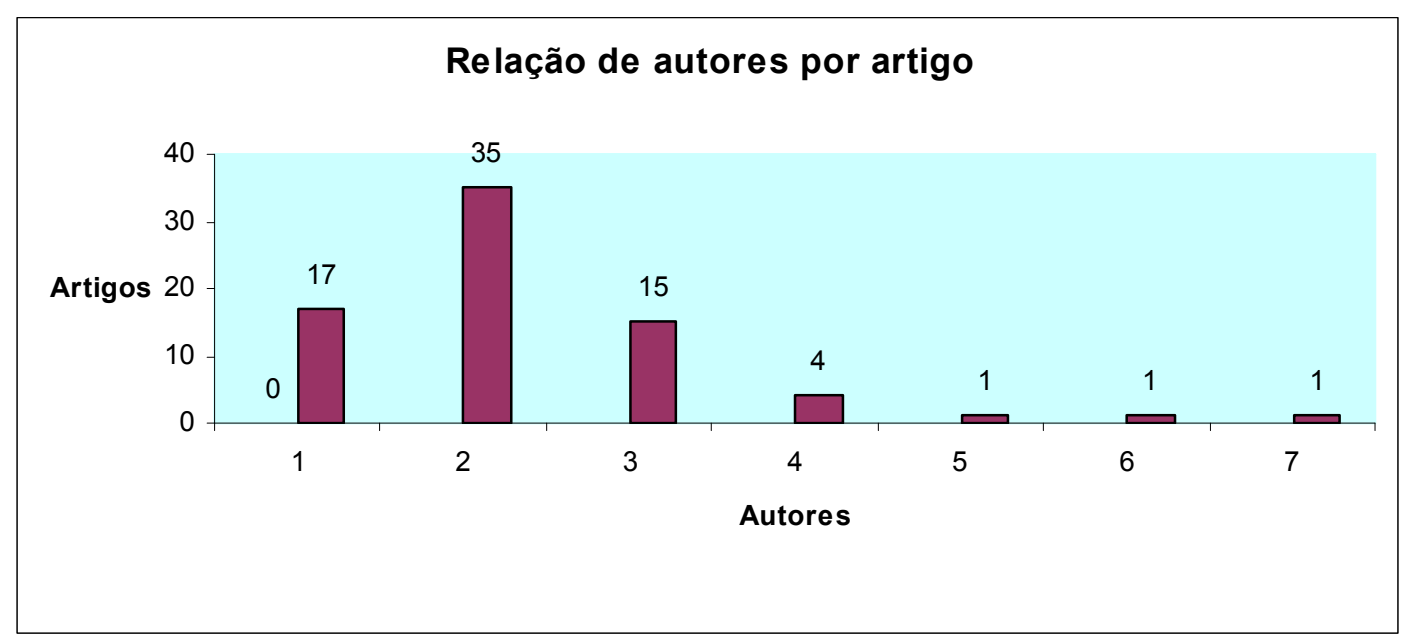

Gráfico 1 - Número de autores por artigo

Fonte: dados da pesquisa.

Do total de 74 artigos, 17 foram produzidos por somente um autor, 35 por dois autores, 15 por três autores, 4 por quatro autores e 1 por cinco, seis e sete autores, respectivamente. Portanto, o tema controladoria foi tratado por diversos autores, sendo que 121 pesquisadores diferentes aprovaram seus artigos nos congressos analisados. Verifica-se que grande parte dos artigos aprovados foram de produção conjunta com outros autores, bem como com diversas origens institucionais. Isso contribui à diversidade de opiniões sobre temas e metodologias, e influi na qualidade dos trabalhos selecionados para publicação.

No que se refere às referências utilizadas nos artigos, os autores que mais foram referenciados nas publicações constam na Tabela 3. 
Tabela 3 - Freqüência de referenciação dos 20 autores mais citados nos artigos

\begin{tabular}{lcc:c}
\hline Nome dos autores & $\begin{array}{c}\text { Nacionalidade } \\
\text { dos autores }\end{array}$ & $\begin{array}{c}\text { Instituição } \\
\text { dos autores }\end{array}$ & $\begin{array}{c}\text { Quantidade de } \\
\text { referências }\end{array}$ \\
\hline Armando Catelli & Brasileira & FEA/USP & 42 \\
Reinaldo Guerreiro & Brasileira & FEA/USP & 31 \\
Masayuki Nakagawa & Brasileira & FEA/USP & 29 \\
Carlos Alberto Pereira & Brasileira & FEA/USP & 26 \\
Sandra Figueiredo & Brasileira & UNIFOR & 24 \\
Clara P. Mosimann & Brasileira & UDESC & 21 \\
Lauro Brito de Almeida & Brasileira & UniFECAP & 19 \\
Stephen Charles Kanitz & Brasileira & FEA/USP & 19 \\
Clóvis Luís Padoveze & Brasileira & UNIMEP & 19 \\
Ilse Maria Beuren & Brasileira & FURB & 17 \\
Charles T. Horngren & Estrangeira & Stanford University & 16 \\
Robert S. Kaplan & Estrangeira & Harvard Business School & 15 \\
Cláudio Parisi & Brasileira & UniFECAP & 15 \\
Nguyen H. Tung & Estrangeira & University of California, & 13 \\
Ivam Ricardo Peleias & San Francisco & 12 \\
Michael E. Porter & Brasileira & UniFECAP & 12 \\
Sérgio de Iudícibus & Estrangeira & Harvard Business School & 12 \\
James D. Willson & Brasileria & FEA/USP & 11 \\
Eliseu Martins & Estrangeria & Instituição não identificada & 11 \\
Robert N. Anthony & Brasileira & FEA/USP & 9 \\
\hline
\end{tabular}

Fonte: dados da pesquisa.

Analisando-se as fontes dos artigos pesquisados, constatou-se que a maioria dos autores referenciados é brasileira e pouca presença de autores estrangeiros dentre as bibliografias mais utilizadas nos artigos. Para uma comparação entre percentuais de referências, a proporção é de $70 \%$ de autores nacionais e $30 \%$ estrangeiros. Resultado esse que conduz a um domínio das literaturas nacionais como meio de consulta pelos pesquisadores, deixando de consultar obras estrangeiras.

Das vezes que foram referenciados autores estrangeiros nos artigos, um modelo muito utilizado na controladoria é o Balanced Scorecard, desenvolvido por Kaplan e Norton (1997). Neste modelo os autores tomam como base as metodologias e o conceito de matrizes matemáticas aplicado ao processo decisório.

Outra diferença da abordagem dos autores estrangeiros é na base conceitual da controladoria e funções do Controller, diferenciando-se em alguns aspectos dos conceitos utilizados por autores nacionais. No Brasil, as funções da controladoria concentram-se no suporte à gestão empresarial, não focalizando usuários externos das informações contábeis.

\subsection{Artigos segundo sua metodologia}

Diante dos vários métodos, técnicas e procedimentos utilizados para investigação científica sobre controladoria, buscou-se padronizá-los conforme classificação de alguns autores de metodologia de pesquisa, pois várias vezes os autores não explicitam de forma clara a metodologia utilizada nos seus trabalhos. Gil (2006) faz um agrupamento geral quanto aos níveis 
ou tipos de pesquisas existentes, classificando-os em: descritivos, exploratórios e explicativos quanto aos objetivos gerais do estudo.

$\mathrm{Na}$ Tabela 4 são mostrados os artigos publicados na área de controladoria durante o ano de 2001 a 2006 com os tipos de pesquisa definidos por Gil (2006). Ainda na Tabela 4 foram classificados os artigos segundos seus delineamentos, os quais podem ser definidos em dois grandes grupos de delineamentos: aqueles que se valem das chamadas fontes de "papel" e aqueles cujos dados são fornecidos por pessoas. Entre os fornecidos por "papel" estão os bibliográficos e documentais, e entre os fornecidos por pessoas, estão os levantamentos, estudos de casos, estudos de campo, experimentais e ex-post-facto (GIL, 2006).

$\mathrm{Na}$ Tabela 4 também é demonstrado o meio de coleta dos dados dos artigos, os quais, segundo Gil (2006), podem ser classificados em: observação, questionário e entrevista. O primeiro meio ou técnica de coleta de dados não foi encontrado nos trabalhos analisados. Questionário, conforme Silva (2003), "é um conjunto ordenado e consciente de perguntas a respeito de variáveis e situações que se deseja medir ou descrever". Entrevista, de acordo com Silva (2003), "é uma comunicação verbal entre duas ou mais pessoas, com um grau de estruturação previamente definido".

Quanto à abordagem do problema, Raupp e Beuren (2006) classificam as pesquisas em qualitativas e quantitativas. Esta classificação foi considerada na investigação da metodologia utilizada pelos autores nos artigos, conforme mostra-se na Tabela 4.

Tabela 4 - Artigos segundo o tipo de pesquisa, procedimentos, técnicas e abordagem

\begin{tabular}{|c|c|c|}
\hline Tipos de pesquisa & $\mathbf{N}$ & $\%$ \\
\hline Descritiva & 32 & 43,24 \\
\hline Exploratória & 38 & 51,35 \\
\hline Explicativa & 4 & 5,41 \\
\hline \multicolumn{3}{|c|}{ Classificação dos artigos quanto ao delineamento ou procedimento } \\
\hline Bibliográfica & 23 & 31,08 \\
\hline Pesquisa de campo & 22 & 29,73 \\
\hline Estudo de caso & 14 & 18,92 \\
\hline Levantamento (survey) & 10 & 13,52 \\
\hline Pesquisa documental & 4 & 5,40 \\
\hline Pesquisa-ação & 1 & 1,35 \\
\hline \multicolumn{3}{|c|}{ Classificação quanto às técnicas de coleta de dados } \\
\hline Questionário & 28 & 37,84 \\
\hline Entrevista & 8 & 10,81 \\
\hline Não identificada & 38 & 51,35 \\
\hline \multicolumn{3}{|c|}{ Classificação quanto à abordagem do problema } \\
\hline Qualitativa & 8 & 10,81 \\
\hline Quantitativa & 10 & 13,51 \\
\hline Não identificada & 56 & 75,68 \\
\hline
\end{tabular}

Fonte: dados da pesquisa.

Diante da análise realizada, verifica-se que as pesquisas do tipo exploratória são as mais freqüentes na área de pesquisa em controladoria, correspondendo a 51,35\% do total; a pesquisa 
descritiva é a segunda mais usada pelos autores, com 42,24\%; e a explicativa com pouca aplicação nas pesquisas em controladoria, representando apenas 5,41\%.

As pesquisas explicativas não são muito comuns na área de controladoria devido ao fato das suas características serem mais aplicadas nas ciências naturais, envolvendo a experimentação. Pode até ser utilizada nas ciências sociais, geralmente com uso da técnica de observação. Nos artigos analisados, quando foi utilizado este tipo de pesquisa, usou-se para explicar como a controladoria pode auxiliar num processo de implantação de gerenciamento de custos, descrevendo e interpretando como pode auxiliar passo a passo o desenvolvimento do projeto.

Quanto aos procedimentos ou delineamentos de pesquisa adotados nos artigos, constata-se que a pesquisa bibliográfica e as pesquisas de campo obtiveram maior participação, com 31,08\% e $29,73 \%$ respectivamente. Os dois delineamentos têm suas vantagens e desvantagens na abordagem da controladoria, sendo que os estudos bibliográficos abrangem uma gama maior de variáveis de estudo do que aquelas pesquisadas em um universo delimitado, pois as fontes de pesquisa são realizadas com base em material já elaborado. Por outro lado, aqueles ignoram novos dados e situações reais ou práticas do dia-a-dia que possam ser relevantes enquanto objeto da pesquisa.

A técnica de coleta de dados mais utilizada pelos autores para elaboração dos trabalhos foi por meio de questionários, com $37,84 \%$ do total de artigos analisados, enquanto que as entrevistas evidenciam-se como uma técnica menos usual para coleta de dados, com apenas $10,81 \%$ dos trabalhos. Uma dificuldade na aferição da técnica de coleta de dados foi a não disponibilidade desta informação nos trabalhos. Na pesquisa documental e na bibliográfica está evidente que não foi aplicado questionário ou entrevista, mas nas demais teria que ter alguma indicação sobre a técnica utilizada, por isso não se apresenta $100 \%$ das análises.

No que concerne à abordagem do problema, também não foi constatada na maioria dos artigos indicação sobre a forma escolhida, se qualitativa ou quantitativa. Nos artigos em que foi explicitada a abordagem, prevaleceu a quantitativa, representando $13,51 \%$ do total dos artigos analisados, contra $10,81 \%$ de qualitativa.

\subsection{Comparação por instituições dos artigos publicados de 2001 a 2006}

$\mathrm{Na}$ Tabela 5 mostra-se um comparativo entre as instituições no que concerne ao número de artigos aprovados nos congressos USP, ENANPAD e CUSTOS no período de 2001 a 2006.

Tabela 5 - Comparação do número e do percentual de artigos das instituições no período de 2001 a 2006 


\begin{tabular}{|c|c|c|c|c|c|c|c|c|c|c|c|c|c|c|}
\hline IES & $\frac{\hat{n}}{\sigma}$ & 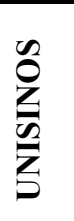 & 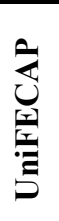 & 点 & 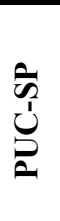 & 㚇 & 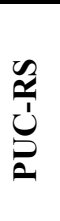 & $\begin{array}{l}\text { Un } \\
\text { Ș } \\
\text { S }\end{array}$ & $\begin{array}{l}0 \\
\frac{\alpha}{5} \\
\frac{\alpha}{5}\end{array}$ & $\underset{S}{U}$ & $\sum_{S}^{\infty}$ & 点 & 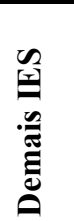 & $\begin{array}{l}\text { Total } \\
2001 \\
\text { a } \\
2006\end{array}$ \\
\hline Ano & $\mathrm{n}^{\circ}$ & $\mathrm{n}^{\circ}$ & $\mathrm{n}^{\circ}$ & $\mathrm{n}^{\circ}$ & $n^{\circ}$ & $\mathrm{n}^{\circ}$ & $n^{\circ}$ & $n^{\circ}$ & $n^{\circ}$ & $\mathrm{n}^{\circ}$ & $\mathbf{n}^{\circ}$ & $\mathbf{n}^{\circ}$ & $\mathrm{n}^{\circ}$ & $\mathrm{n}^{\circ}$ \\
\hline 2001 & 3 & 0 & 1 & 0 & 2 & 0 & 0 & 1 & 1 & 0 & 1 & 0 & 3 & 12 \\
\hline 2002 & 3 & 0 & 0 & 3 & 1 & 0 & 1 & 1 & 1 & 0 & 0 & 0 & 3 & 13 \\
\hline 2003 & 5 & 1 & 1 & 0 & 0 & 1 & 0 & 0 & 0 & 1 & 0 & 0 & 1 & 10 \\
\hline 2004 & 2 & 0 & 1 & 3 & 0 & 0 & 0 & 0 & 0 & 0 & 0 & 0 & 1 & 7 \\
\hline 2005 & 5 & 5 & 2 & 0 & 1 & 1 & 1 & 0 & 0 & 0 & 0 & 1 & 1 & 17 \\
\hline 2006 & 3 & 4 & 1 & 0 & 0 & 0 & 0 & 0 & 0 & 1 & 1 & 1 & 4 & 15 \\
\hline TOTAIS & 21 & 10 & 6 & 6 & 4 & 2 & 2 & 2 & 2 & 2 & 2 & 2 & 13 & 74 \\
\hline$(\%)$ & 28,5 & 13,5 & 8,1 & 8,1 & 5,3 & 2,7 & 2,7 & 2,7 & 2,7 & 2,7 & 2,7 & 2,7 & 12,2 & $100 \%$ \\
\hline
\end{tabular}

Fonte: dados da pesquisa.

Pela Tabela 5 nota-se a dispersão de participação entre as instituições no decorrer dos anos. Observa-se que a USP possui percentual de participação maior no período pesquisado, seguida pela UNISINOS, UniFECAP e UNB. Essas quatro instituições juntas possuem 58,20\% de todos os artigos publicados sobre controladoria com base nos critérios de selção adotados na pesquisa. Destaque também para a região Sudeste (São Paulo), com a USP e a UniFECAP, entre as três que mais obtiveram participação nos trabalhos analisados.

A coluna que demonstra as demais instituições refere-se às instituições com apenas um artigo publicado no período pesquisado. As outras instituições relacionadas nas outras colunas, todas possuem mais de um artigo, por isso mostra-se a evolução de cada instituição nos congressos considerados.

$\mathrm{Na}$ Tabela 6 faz-se uma comparação anual das publicações das instituições com maior destaque durante os anos de 2001 a 2006. Comparam-se os percentuais de participação anual, diferenciando-se da Tabela 5 onde foram comparados os totais gerais de participação das instituições.

Tabela 6 - Comparação anual do percentual de artigos publicados pelas instituições

\begin{tabular}{|c|c|c|c|c|c|c|c|c|c|c|c|c|c|c|}
\hline IES & $\hat{\tilde{n}}$ & 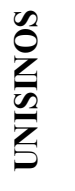 & 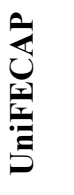 & 竞 & 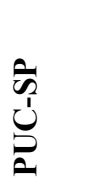 & $\begin{array}{l}\text { 号 } \\
\text { 竞 }\end{array}$ & 晃 & $\begin{array}{l}\text { U } \\
\text { S }\end{array}$ & $\begin{array}{l}0 \\
\frac{\pi}{5} \\
S\end{array}$ & ب & $\sum_{S}^{\infty}$ & 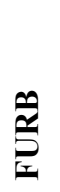 & 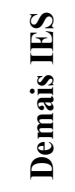 & Total \\
\hline Ano & $\%$ & $\%$ & $\%$ & $\%$ & $\%$ & $\%$ & $\%$ & $\%$ & $\%$ & $\%$ & $\%$ & $\%$ & $\%$ & $\%$ \\
\hline 2001 & 25 & 0 & 8,4 & 0 & 16,7 & 0 & 0 & 8,3 & 8,3 & 0 & 8,3 & 0 & 25 & 100 \\
\hline 2002 & 23 & 0 & 0 & 23,1 & 7,7 & 0 & 7,7 & 7,7 & 7,7 & 0 & 0 & 0 & 23,1 & 100 \\
\hline 2003 & 50 & 10 & 10 & 0 & 0 & 10 & 0 & 0 & 0 & 10 & 0 & 0 & 10 & 100 \\
\hline 2004 & 28,6 & 0 & 14,3 & 42,9 & 0 & 0 & 0 & 0 & 0 & 0 & 0 & 0 & 14,2 & 100 \\
\hline 2005 & 29,4 & 29,4 & 11,8 & 0 & 5,9 & 5,9 & 5,9 & 0 & 0 & 0 & 0 & 5,9 & 5,8 & 100 \\
\hline 2006 & 20 & 26,7 & 6,6 & 0 & 0 & 0 & 0 & 0 & 0 & 6,6 & 6,7 & 6,7 & 26,7 & 100 \\
\hline
\end{tabular}

Fonte: dados da pesquisa. 
Para essa análise levaram-se em consideração apenas os artigos publicados no ano. Por exemplo, 3 artigos publicados pela USP no ano 2001 em relação ao total geral de artigos neste ano que foram 12, o percentual foi obtido da seguinte forma: $3 \div 12$ x $100=25 \%$. Foram avaliadas algumas características no decorrer da Tabela 6 , como por exemplo, a regularidade e domínio da publicação de algumas universidades no País, como a USP e UNISINOS, destacandose a falta de publicações por outras instituições.

Analisando os dados expostos na Tabela 6, verifica-se que no período de pesquisa (2001 a 2006) a Universidade de São Paulo foi a que mais expôs trabalhos nos eventos pesquisados. A composição acumulada até 2006 está estabelecida na Tabela 7.

Tabela 7 - Comparação acumulada entre USP e demais instituições no período de 2001 a 2006

\begin{tabular}{c|c|c|c}
\hline Ano & USP (acumulado) & Demais (acumulado) & Total (acumulado) \\
\hline 2001 & $3(25,00 \%)$ & $9(75,00 \%)$ & $12(100 \%)$ \\
\hline 2002 & $6(24,00 \%)$ & $19(76,00 \%)$ & $25(100 \%)$ \\
\hline 2003 & $11(34,37 \%)$ & $21(65,63 \%)$ & $32(100 \%)$ \\
\hline 2004 & $13(30,95 \%)$ & $29(69,05 \%)$ & $42(100 \%)$ \\
\hline 2005 & $18(30,51 \%)$ & $41(69,49 \%)$ & $59(100 \%)$ \\
\hline 2006 & $21(28,38 \%)$ & $53(71,62 \%)$ & $74(100 \%)$ \\
\hline
\end{tabular}

Fonte: dados da pesquisa.

Observa-se que, mesmo com o surgimento de novos cursos, praticamente não houve alteração na participação da USP no decorrer dos congressos, embora se vislumbre que sua participação e domínio das publicações seja diluída no decorrer dos anos. Parece natural e compreensível que a participação da USP nos dados acumulados diminua no tempo. É possível que esse cenário modifique-se com a consolidação de Cursos já existentes e a criação de novos Cursos de Mestrado e Doutorado em Ciências Contábeis.

\subsection{Análise do conteúdo dos artigos}

Neste tópico procede-se à análise dos artigos quanto ao seu enfoque em controladoria, confirmando sua interdisciplinaridade com várias áreas. Diante dessa característica da controladoria, constatou-se nos trabalhos uma diversificação dessa interdisciplinalidade, conforme evidencia-se na Tabela 8. 
Tabela 8 - Enfoque dos artigos analisados

\begin{tabular}{l|c}
\hline \multicolumn{1}{c|}{ Enfoque } & $\mathbf{N}^{\circ}$ de artigos \\
\hline Processo de gestão & 10 \\
Funções do controller & 9 \\
Gestão organizacional & 9 \\
Sistemas de informações & 9 \\
Gestão empresarial & 7 \\
Gestão publica & 6 \\
Gestão de custos & 5 \\
Gestão do risco & 4 \\
Evolução da controladoria & 4 \\
Governança corporativa & 4 \\
Gestão IES & 3 \\
Gestão econômica & 2 \\
Planejamento tributário & 2 \\
\hline
\end{tabular}

Fonte: dados da pesquisa.

Analisando-se os enfoques dados pelos autores em seus artigos na Tabela 8, nota-se uma dispersão dos assuntos relacionados à controladoria. Comparando-se as funções da controladoria pode-se fazer uma análise entre as constatadas nos artigos e as funções segundo conceitos de alguns autores. Processo de gestão foi o enfoque com maior aplicação nos artigos pesquisados e destaca-se como uma função essencial em que a controladoria dá suporte.

Logo em seguida, outro assunto bastante pesquisado, diz respeito às funções do controller, com nove artigos, também identificando-se como figura principal para o desenvolvimento da controladoria. Com igual número constam gestão organizacional e sistemas de informações, ambos com nove artigos. Enfim, vários foram os assuntos tratados nos artigos, confirmando uma diversidade do campo de atuação da controladoria.

Considerando os enfoques encontrados nos artigos, realiza-se na seqüência uma síntese do que foi abordado, bem como sua relação com a controladoria. Não se procurou interferir com opiniões em relação aos achados, mas sim traçar algumas características do que os pesquisadores investigaram.

a) Processo de Gestão

Uma das funções da controladoria é prover e gerenciar informações de controle e avaliação de desempenho organizacional. Nesse aspecto foi identificado como a controladoria pode contribuir para estruturar o processo de gestão nas organizações, e também averiguar a prática dos conceitos de controladoria no âmbito das entidades. Foram dez trabalhos com essa abordagem, entre os quais algumas diferenças sobre seus objetivos de investigação foram percebidas, como gerenciar os tipos de riscos que afetam as empresas e o papel da controladoria nesse contexto. Outro trabalho, com uma abordagem diferente, analisou se a controladoria utilizase do processo de raciocínio da Teoria das Restrições na estruturação do processo de gestão das empresas.

b) Funções do Controller

O enfoque mostra que a profissão do Controller foi assunto relevante para os pesquisadores. Comentários que se pode expressar a respeito desses resultados é a importância do 
mesmo nas organizações, ou em qualquer outra área onde o mesmo esteja inserido, pois a sociedade ou as empresas demandam diferentes tipos de serviços de profissionais, com diferentes tipos de responsabilidades, e estes profissionais precisam de requisitos mínimos para exercerem sua profissão. Grupos de conhecimentos do controller, adequação da carga horária na IES também foi objeto de estudo. Outro trabalho investigou a percepção dos controllers de empresas industriais relativamente aos diversos aspectos da decisão de bonificação em quantidade de produto, a importância do papel do controller na gestão e geração de lucros. Comparação de organogramas empresariais e onde o perfil do controller se encaixa no contexto organizacional atual brasileiro, também foi pesquisado. Todas essas foram abordagens feitas em relação ao controller, dada sua importância nas atribuições da controladoria.

\section{c) Gestão Organizacional}

Dentre as abordagens dos artigos analisados, esta foi uma que também teve bastante aplicação pelos autores em seus trabalhos, pois nove artigos trataram da Controladoria aplicada à gestão organizacional. A maioria dos objetivos verificados nos trabalhos diz respeito à contribuição que a controladoria pode exercer no planejamento, organização e controle das organizações, que são preocupações constantes dos gestores e pesquisadores. Outro assunto verificado pelos pesquisadores é quanto à estrutura das organizações e a capacidade da controladoria em otimizar e gerenciar melhor as informações, também contribuindo assim para a interação entre as áreas organizacionais.

\section{d) Sistemas de Informações}

Dentre os vários objetivos dos sistemas de informações obtidos a partir da controladoria nas organizações, nos trabalhos analisados, foram discutidos alguns aspectos relevantes a serem considerados pela controladoria das organizações na coordenação do desenvolvimento e manutenção de sistemas de informações sobre concorrentes. Constataram que grande parte das empresas confere tratamento informal à análise da concorrência; assim, as informações acabam ficando dispersas, o que reduz drasticamente o seu potencial de contribuição para a formulação de estratégias. Nos demais trabalhos foi pesquisado como o sistema de informações da controladoria pode dar suporte à gestão organizacional de forma que sejam atingidos os objetivos de otimização de resultados. Outro trabalho procurou entender como os gestores podem utilizar as informações de forma eficaz para seus empreendimentos.

\section{e) Gestão Empresarial}

Foram quatro artigos no total com abordagem sobre gestão empresarial. Em um dos artigos, tratou-se de um estudo de caso onde os pesquisadores observaram o modelo de gestão adotado pela Organização Odebrecht, cuja análise se realizou sob o enfoque gerencial do estudo das práticas de controladoria. No referido trabalho os pesquisadores analisaram se o método interno de planejamento, execução, cumprimento das metas, assemelhava-se ao Modelo de Gestão Econômica - GECON. Foi destacada também a valorização da controladoria na gestão empresarial, ao orientar os gestores em decisões a serem tomadas, e salientar a influência das projeções do fluxo de caixa da empresa, nas opiniões do Controller. Outro trabalho buscou demonstrar a necessidade de se ter um gerenciamento integrado entre os diversos tipos de riscos que afetam as empresas e o papel da controladoria nesse contexto, indo além dos aspectos financeiros, cobrindo situações de riscos operacionais e estratégicos. 


\section{f) Gestão Pública}

A controladoria contribui para a administração pública, principalmente quando tem pessoas com visão de equilíbrio financeiro em seu comando. Nesta abordagem seis artigos propuseram utilizar a controladoria no auxílio da gestão pública. Em um dos trabalhos foi relatada a implantação de uma secretaria de controladoria de apoio à administração municipal e também com intuito de melhorar os serviços prestados à comunidade, com ênfase de combate de desperdícios de gastos públicos e sua capacidade de organização. Nos outros trabalhos, através da controladoria, buscaram-se várias soluções para os problemas da administração pública, como por exemplo, desenvolvimento de modelos de relatórios que façam previsões sobre as condições mínimas da situação financeira de alguns municípios pernambucanos. Outros artigos procuraram evidenciar que a controladoria pode contribuir na gestão de programas sociais ao evidenciar o impacto dos programas sociais na renda econômica e financeira das famílias contempladas. Para responder essa questão, utilizaram-se modelos de controladoria aplicados à gestão governamental, como a ótica da gestão econômica (GECON); doutrina institucionalista; e normas definidoras das instituições em apreço.

\section{g) Gestão de Custos}

Nesse objetivo fundamental das organizações, ou seja, a gestão de custos, a controladoria exerce influente papel para as organizações. Alguns artigos procuraram analisar e otimizar o seu potencial de lucro em função da minimização das perdas decorrentes de seus processos, e como a controladoria enquanto gestora das informações pode assegurar aos gestores o melhor caminho para eliminação dos desperdícios de recursos. Apresentaram-se também algumas características necessárias pelos sistemas de custeio para uso de informações estratégicas sobre o desempenho de alguns setores de produção.

\section{h) Gestão do risco}

As pesquiss realizadas relacionadas à gestão de risco tiveram como foco central os controles internos preconizados pela Lei Sarbanes Oxley, para contribuir na gestão do risco dos negócios e da própria gestão. Foram realizados estudos de casos para identificar os tipos de controles implantados e as formas de sua implantação em organizações. Observa-se o papel da controladoria na gestão do risco nas pesquisas realizadas.

\section{i) Evolução da Controladoria}

Foram pesquisadas nesta abordagem o perfil da controladoria nas organizações, buscando discutir seu papel no controle de gestão das empresas. Identificar o atual estágio de desenvolvimento da controladoria e sua missão, principais crenças e valores, a existência do planejamento estratégico dentro das empresas. Os resultados alcançados levam a concluir que as empresas possuem dificuldades em várias definições de sua gestão, como por exemplo, as definições de missões, crenças e valores organizacionais, resultando em problemas em seu planejamento e falta de coerência em seu modelo de gestão.

\section{j) Governança Corporativa}

Nos artigos analisados constatou-se que dentro dessa abordagem ocorreram diferentes tipos de tratamentos à controladoria. Por exemplo, um artigo investigou a aplicabilidade de indicadores de governança em pequenas e médias empresas através da controladoria. Constatouse que a governança corporativa representa uma abordagem nova de gestão, que viabiliza a maximização do valor do negócio e da riqueza do acionista/cotista. Contribui para o cumprimento 
do papel social das organizações e que, para o seu efetivo exercício, a empresa necessita de informações de qualidade independente do tamanho da empresa. Também houve outro artigo no qual os autores fizeram um levantamento comparativo entre a controladoria como um mecanismo interno de Governança Corporativa entre empresas de capital brasileiro e norte-americano. Chegaram à conclusão que a controladoria pode ser considerada como um mecanismo interno de governança voltado ao provimento de transparência nas divulgações dos atos administrativos.

\section{k) Gestão IES}

Nessas pesquisas os autores pretendiam identificar e avaliar o impacto de um Mestrado Acadêmico em Controladoria e Contabilidade Estratégica na carreira profissional de seus egressos. Observaram que parcela significativa dos egressos que antes atuavam apenas no meio empresarial, passou a atuar também no meio acadêmico, e os principais motivos apontados para alavancagem da carreira profissional foram a ampliação de conhecimento, novos contatos e/ou oportunidades. Em outro trabalho, os pesquisadores buscaram identificar quais as expectativas de alunos de graduação ao cursar uma pós-graduação em controladoria. Constataram que os alunos mostram-se interessados em seguir carreira acadêmica e que não se satisfazem somente com a graduação, que não atinge os objetivos do mercado.

\section{CONSIDERAÇÕES FINAIS}

Utilizando-se os parâmetros considerados necessários para a realização da presente pesquisa, constatou-se a inserção da controladoria em anais de eventos científicos nacionais relacionados à área de contabilidade, conforme a proposta inicial do trabalho. Nesta pesquisa descritiva, realizada por meio de levantamento, com abordagem quantitativa e qualitativa, chegou-se a um panorama de algumas características dos artigos publicados nos eventos escolhidos pela pesquisa, os quais revelaram:

a) que houve um crescimento proporcionalmente maior de artigos de controladoria, levando-se principalmente em consideração os dois últimos anos, 2005 e 2006, sendo também os anos com maior número de artigos publicados durante o período pesquisado. Fato esse que reforça a ênfase dada nesse período à avaliação quantitativa da produção científica na avaliação dos Programas de Pós-Graduação pela CAPES (Coordenação de Aperfeiçoamento de Pessoal de Nível Superior, fundação do Ministério da Educação, no Brasil) e o surgimento de novos Cursos de Mestrado em Contabilidade;

b) na análise da metodologia utilizada pelos autores em seus artigos, buscou-se padronizála conforme a concepção de alguns autores da área de metodologia, pois as dificuldades de encontrar a metodologia nos artigos foram barreiras na análise. Ressalta-se que em artigos científicos ou qualquer outro trabalho que venha a ser posteriormente consultado pelos mais diferentes tipos de leitores, com os mais variados tipos de conhecimentos, deve-se deixar explícito o modo como se chegou às conclusões obtidas a partir do estudo. Atribui-se o aspecto constatado nos artigos como uma deficiência ou dificuldade por parte de autores de artigos científicos de contabilidade, e aqui especificamente na área de controladoria, em classificar seus trabalhos quanto à metodologia;

c) na análise do conteúdo, em que se relatou o que os artigos abordaram em relação ao tema controladoria, observou-se que o campo de atuação da controladoria não se limita somente a um tipo isolado de organização. Além disso, que ainda se demanda de mais pesquisas para chegar a um consenso sobre a concepção de vários aspectos do tema, particularmente às funções $\mathrm{e}$ artefatos da controladoria. 
O presente estudo não realizou uma avaliação da qualidade dos artigos nacionais de controladoria. Porém, acredita-se que esta análise seja útil, principalmente para facilitar o conhecimento de critérios e variáveis adequadas à avaliação dos artigos em anais de congressos. Espera-se que a discussão do estado-da-arte dos artigos nacionais de controladoria contribua para o seu aperfeiçoamento.

Recomenda-se que estudos sobre a produção científica em Ciências Contábeis sejam realizados como forma de se apresentar, descrever, qualificar e quantificar as pesquisas. A literatura e pesquisas científicas proporcionam discussões e geram novas interpretações das teorias e abordagens já consagradas. Por isso há necessidade e decorre o aprimoramento contínuo e a evolução da ciência

\section{REFERÊNCIAS}

ALMEIDA, L. B.; PARISI, C.; PEREIRA, C. A. Controladoria. In: CATELLI, A. Controladoria: uma abordagem da gestão econômica - GECON. São Paulo: Atlas, 2001. p. 34355.

BEUREN, I. M. O papel da controladoria no processo de gestão. In: SCHMIDT, P. Controladoria: agregando valor para a empresa. Porto Alegre: Bookman, 2002. p. 16-38.

CASTRO, C. M. Ciência e universidade. Rio de Janeiro: Zahar, 1985. 56 p.

GIL, A.C. Métodos e técnicas de pesquisa. 5 ed. São Paulo: Atlas, 2006.

KAPLAN, R.; NORTON, D. P. A estratégia em ação: balanced scorecard. Rio de Janeiro: Campus, 1997.

MARTINS, G. A., SILVA, R. B. C. da. Plataforma teórica: trabalhos dos $3^{\circ}$ e $4^{\circ}$ congressos USP de controladoria e contabilidade: um estudo bibliométrico - SP. In: CONGRESSO USP DE CONTROLADORIA E CONTABILIDADE, 5., 2005, São Paulo. Anais... São Paulo: FEA/USP, 2005. CD-ROM.

MORIKI, A. M. N.; MARTINS, G. A. Análise do referencial bibliográfico de teses e dissertações sobre Contabilidade e Controladoria. In: CONGRESSO USP DE CONTROLADORIA E CONTABILIDADE, 3., 2003, São Paulo. Anais. São Paulo: FEA/USP, 2003. CD-ROM.

MOSIMANN, C.P.; FISCH, S. Controladoria: seu papel na administração de empresas. São Paulo: Atlas, 1999.

MUGNAINI, R.; JANNUZZI, P.; QUONIAM L. Indicadores bibliométricos da produção científica brasileira: uma análise a partir da base Pascal. Disponível em:< http://www.scielo.br/pdf/ci/v33n2/a13v33n2.pdf> Acesso em: 16 ago. 2006.

PRITCHARD, A. Statistical bibliography or bibliometrics. Journal of Documentation, London, v. 25, n. 4, p. 348-349, Dec. 1969.

RAUPP, F. M.; BEUREN, I. M. Metodologia da pesquisa aplicável às ciências sociais. In: BEUREN, I. M. (Org.). Como elaborar trabalhos monográficos em contabilidade: teoria e prática. 3 ed. São Paulo: Atlas, 2006. p. 76-97. 
SANCHO, Rosa. Indicadores bibliométricos utilizados em la evaluación de la ciência y la tecnología: revisión bibliográfica. Revista Española de Documentación Cientifica, Madrid, v. 13, n. 3-4, p. 842-865, 1990.

SILVA, A. C. R. Metodologia da pesquisa aplicada à contabilidade. São Paulo, Atlas, 2003. 